\title{
Article
}

\section{Spatial analysis of degradation in the Reserve for San Rafael National Park, period 2005-2019}

\author{
Tania Jeannette Llamas Franco ${ }^{*}$, Lucía Janet Villalba Marín², Stella Mary Amarilla Rodríguez², Lidia Florencia \\ Pérez de Molas ${ }^{3}$, Lourdes González Soria ${ }^{3}$, Erick Bullock ${ }^{4, *}$ \\ 1 Llamas, Tania; National University of Asuncion, Faculty of Agricultural Sciences, Forest Engineering Career. \\ San Lorenzo, Paraguay; taniaallamas@gmail.com \\ 2 National University of Asuncion, Faculty of Agricultural Sciences, Direction of Postgraduate. San Lorenzo, \\ Paraguay; janet.villalba@agr.una.py; stella.amarilla@agr.una.py \\ 3 National University of Asuncion, Faculty of Agricultural Sciences, Forest Engineering Career: Department \\ of Forests and Biodiversity; lidia.perezmolas@agr.una.py; lourdes.gonzalez@agr.una.py, \\ 4 University of Boston, Massachusetts, United States; bullocke@bu.edu \\ * Correspondence: taniaallamas@gmail.com; Tel.: +59-99-71-473-152
}

\begin{abstract}
The goal of this study was to analyze the forest degradation in the Reserve for San Rafael National Park, Paraguay, during the period 2005-2019. This Reserve is one of the most important forest remnants of the Upper Paraná Atlantic Forest Ecoregion. A multitemporal analysis of degradation was carried out due to the occurrence of three disturbances: forest fires, a twister and illicit crops, using the Continuous Degradation Detection (CODED) algorithm, for which 3 factors were considered: variations due to pixel in the NDFI index values before, during and after every disturbance registered. In this context, the phenomenon with the greatest impact in terms of magnitude of degradation were the forest fires of 2005, being that year at the same time, the one that reported the highest degradation values. Secondly, there are the illicit crops established until the first semester of 2019, and lastly, the twister that occurred in 2017. Our findings demonstrate that CODED algorithm can detect multi-temporal degradation events in a Subtropical Broadleaf Forest, and the postdisturbance regeneration process after every disturbance tends to occur immediately. The response in terms of degradation-regeneration is highly variable, depending of the nature and severity of each disturbance and the vegetation recovery dynamics.
\end{abstract}

Keywords: forest degradation, NDFI index, multitemporal analysis, Continuous Degradation Detection, Google Earth Engine.

\section{Introduction}

The NDFI (Normalized Difference Fraction Index) is a spectral index of degradation, and it has the ability to synthesize information from satellite imagery, allowing the mapping of logging and damage caused to the forest canopy. Spectral mixing models are like a linear combination of spectral signatures called "endmembers". With the choice of the "endmembers", the coefficients of the linear combination are interpretable as fractions of the land cover $[\underline{1}, \underline{2}, \underline{3}]$.

The CODED (Continuous Degradation Detection) algorithm is an open source algorithm executable on the Google Earth Engine platform. It was designed to use Landsat images of 30 meters of resolution. Detection of change (deforestation or degradation), is made using regression coefficients to predict multitemporal observations of the NDFI index. In this way, the algorithm is executed online, which means that the change is controlled sequentially in time using data available in the platform itself [4]].

On a global scale, the NDFI spectral index has been used to detect changes in the structure of tropical forests and detect degradation patterns, either with Landsat or MODIS images $[\underline{5}, \underline{6}, \underline{]}]$. In Latin America, it has been used in investigations to monitor 
forest degradation and deforestation, mainly in the Brazilian Amazon, and to detect selective extraction activities in areas with forest management plans. Landsat images are the most used due to their availability, allowing multitemporal studies to be carried out [ $\underline{8}$, 9].

In Paraguay, there has been an increase in forest degradation during the last decades, affecting the quality of the forests and producing structural changes in them [10]. This is mainly due to the overexploitation of wood to obtain firewood and charcoal, which are the main sources of energy on which more than 51\% of Paraguayan households depends [11].

The San Rafael National Park Reserve in Paraguay is considered one of the main conservation priorities, due it constitutes a representative sample of the biodiversity of the Upper Parana Atlantic Forest (BAAPA). It is floristic richness is among the highest in the country [12], and it is estimated that the different plant formations all present some degree of degradation due to human activities. In the absence of definitions, defined assessment methods and limited data, forest degradation is a complex problem to address, so it is important to generate solid knowledge about this phenomenon.

In that context, just a few countries have the capacity to report the forest areas affected by this phenomenon and the degree of degradation of their resources. The information available is still limited, which is why implementing methodologies to monitoring the historical and current levels of degradation of forests and their remnants, through the use of remote sensors, is a priority.

The applications of the CODED algorithm allow to analyze retrospective and current geospatial data about the state of the forests that are within the study area. The identification and prioritization of factors and phenomena that contribute to forest degradation, and that are considered "critical", make it possible to evaluate the effectiveness of forest management and conservation.

The general goal of the study was to analyze the forest degradation in the Reserve for San Rafael National Park, Paraguay, during period 2005-2019. Specifically, the goals were to: 1) describe the multitemporal behavior of NDFI index values with respect to 3 registered forest disturbances; and 2) analyze forest disturbances in terms of magnitude of degradation.

\section{Materials and Methods}

\subsection{Study area}

The research was carried out in San Rafael National Park Reserve (RPNSR), which is located in the Eastern Region of the Paraguayan Republic at $380 \mathrm{~km}$ from the City of Asunción (Capital). To the north of Itapúa Department covers the districts of Alto Vera, Itapúa Poty and San Pedro del Paraná, and to the south of the Department of Caazapá covers the district of Tavai (Figure 1). The main access road corresponds to number 1 "Mariscal Francisco Solano López".

The RPNSR is one of the largest Protected Wild Areas of the BAAPA Ecoregion, and is part of one of the most important freshwater reservoir basins, called the Guaraní aquifer, with several streams that irrigate the area. Its central location coordinates are $55^{\circ}$ $42^{\prime} 58.43$ "west longitude and $26^{\circ} 26^{\prime} 57.17^{\prime \prime}$ south latitude and occupies an approximate area of 66.575 hectares $[\underline{13}, \underline{14}]$. 


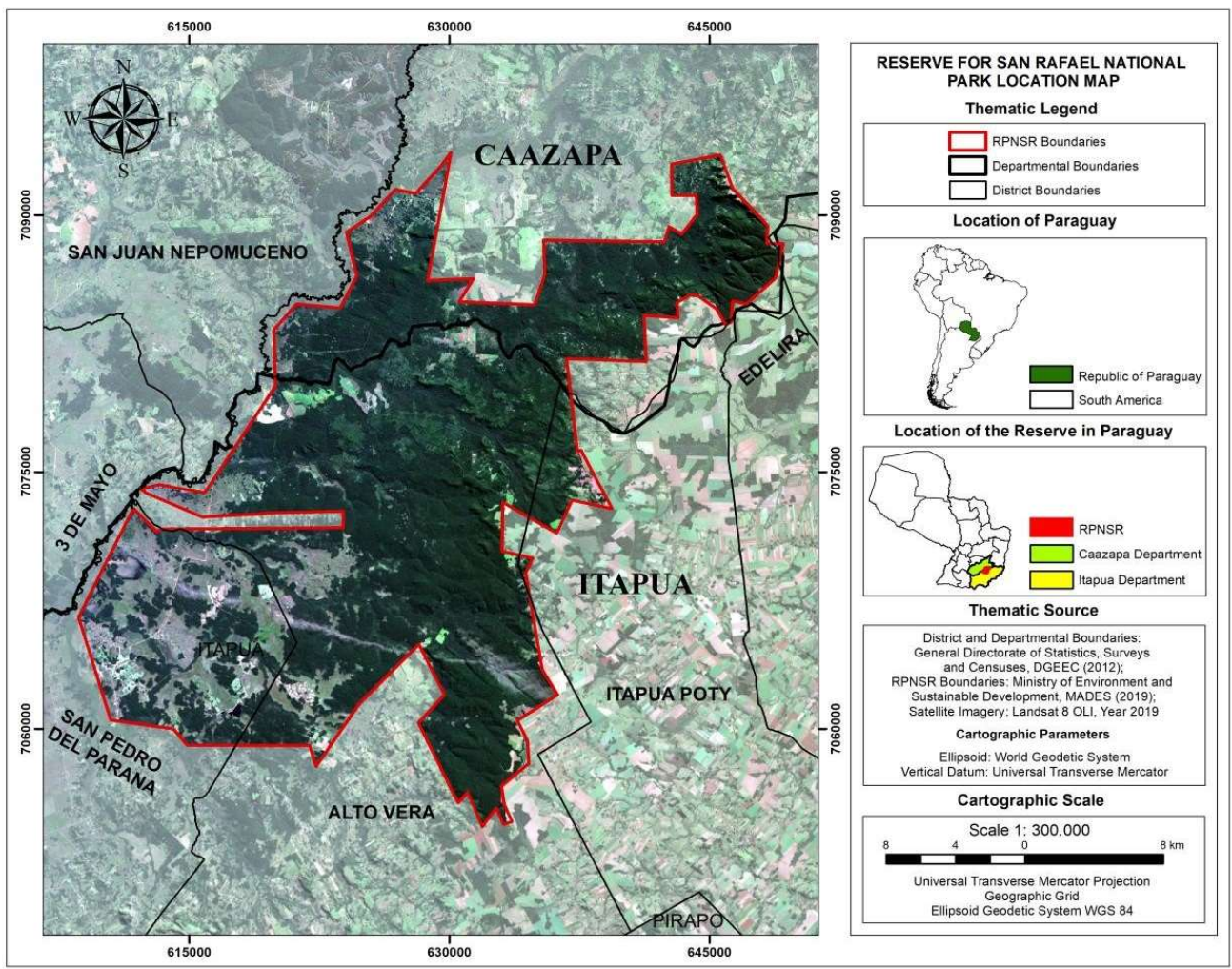

Figure 1. Study area of San Rafael National Park in Paraguay.

It is made up of two main natural communities: grasslands and forest. The first belongs to the ecoregion called Mesopotamian Grasslands, and the forest is part of the socalled Upper Paraná Atlantic Forest (BAAPA) [1]․

The forest is known as "Subtropical Broadleaf Forest". It is the predominant type of vegetation, occupying approximately $80 \%$ of the RPNSR. It includes a variety of habitats: primary forests, with 20 meters high trees, closed canopy and open undergrowth; degraded forests, with trees between 15-19 meters high, open canopy and closed undergrowth, gallery forests and natural forest islands. It is composed of three types of plant communities, which, according to the Rapid Ecological Assessment [16], are: Subhumid Forest, Forest Seasonally Saturated, and Forest Seasonally Flooded.

\subsection{Data}

The Landsat L1T image collection available on the Google Earth Engine platform was used. These have a correction based on control points, digital terrain models and a topographic correction for the displacement of the terrain by the relief $[\underline{17} \underline{18}]$.

Subsequently, the images were filtered by date ".filterDate", region ".filterBounds" and percentage of clouds less than $20 \%$ ".filterMetadata". The ".FeatureCollection" function was used to delimit the area of interest, defining as a mask the official RPNSR shapefile available in the Geoportal of the Ministry of Environment and Sustainable Development (2019), taking into account that this is the institution in charge of the application of on Protected Wild Areas [19].

\subsection{Selection and analysis of disturbances}

The three disturbances considered were: forest fires that occurred in 2005, a twister that occurred in 2017, and illicit crops established until the first semester of 2019. Every disturbance was spatially delimited with the ArcGIS $10.3{ }^{\circledR}$ software. In the next stage was selected the "Time Series Explorer" tool, implemented on the Google Earth Engine 
platform. It allows selecting a geographic point for the temporal analysis of the NDFI Index and its components: Green Vegetation (GV), Non- photosynthetic Vegetation (NPV), Soil and Shadow [9].

A pixel covering a total area of 900 square meters was selected for each disturbance that occurred in the RPNSR and a multitemporal analysis was carried out, for which 3 factors were considered: the variations in the index values before, during and after registered disturbance.

For this study, it is considered that the vegetation has suffered damage to the canopy and is degraded within the range of NDFI values between 0 and 0.75 . This range of NDFI values was empirically defined using canopy damage data collected by conducting forest inventories and their correlation with values reported by the NDFI index []ㅡ. A time period was selected for the analysis of each disturbance (Table 1).

Table 1. Analysis period selected for each disturbance

\begin{tabular}{lcc}
\hline $\begin{array}{l}\text { Registered } \\
\text { disturbance }\end{array}$ & $\begin{array}{c}\text { Year of } \\
\text { occurrence }\end{array}$ & Analysis period \\
\hline Forest fires & 2005 & $2000-2005-2019^{*}$ \\
Twister & 2017 & $2015-2017-2019^{*}$ \\
Illicit crops & $2019^{*}$ & $2010-2015-2019^{*}$ \\
\hline * The year 2019 was only partially considered, from January to June.
\end{tabular}

\subsection{Magnitude analysis}

The interpretation tool and algorithm code used were adapted from github.com/bullocke/coded. For the analysis of the magnitude of affectation resulting from the occurrence of each disturbance, training samples were taken from the coverage observed in each affected area, and the parameters for the execution of the CODED algorithm were defined in the user interface, which below are cited with the respective assigned values (Table 2).

Table 2. Selected parameters to run the CODED algorithm

\begin{tabular}{|c|c|c|}
\hline Parameters & Definition & Assigned values \\
\hline cfThreshold & $\begin{array}{l}\text { minimum threshold to remove clouds } \\
\text { based oncloud fraction }\end{array}$ & 0.05 \\
\hline consec & $\begin{array}{l}\text { consecutive observations beyond change } \\
\text { threshold to trigger a change }\end{array}$ & 4 \\
\hline end & ending year of study period & 2019 \\
\hline forestLabel & label of forest in training data & 1 \\
\hline $\operatorname{minObs}$ & $\begin{array}{l}\text { the minimum number of observations } \\
\text { to fit a modelfor training }\end{array}$ & 6 \\
\hline minYears & minimum years between disturbances & 3 \\
\hline numChanges & $\begin{array}{l}\text { maximum number of changes to keep } \\
\text { whenexporting }\end{array}$ & 2 \\
\hline start & beginning year of study period & 2000 \\
\hline thresh & $\begin{array}{l}\text { change threshold defined as a residual } \\
\text { normalized by the training model RMSE }\end{array}$ & 3 \\
\hline trainDataEnd & $\begin{array}{l}\text { ending year of time period associated } \\
\text { with trainingdata }\end{array}$ & 2019 \\
\hline trainDataStart & $\begin{array}{l}\text { beginning year of time period associ- } \\
\text { ated with training data }\end{array}$ & 2000 \\
\hline trainLength & number of years in training period & 3 \\
\hline
\end{tabular}




\begin{tabular}{llc}
\hline Parameters & \multicolumn{1}{c}{ Definition } & Assigned values \\
\hline \multirow{2}{*}{ window } & the max number of years to use in the & 2 \\
& monitoring period at any given time & \\
\hline
\end{tabular}

Unlike the multitemporal monitoring of the NDFI index (by point), to determine the magnitude of each disturbance, the analysis was carried out by regions. Were considered the forest fires in the northeast area of the Reserve, the tornado in its entirety in the southern area, and illicit crops in the north zone.

\section{Results and Discussion}

\subsection{Multitemporal behavior of the NDFI index respect to forest disturbances}

The time series of the NDFI index values respect to the forest fires that occurred in 2005 is shown in Figure 2.

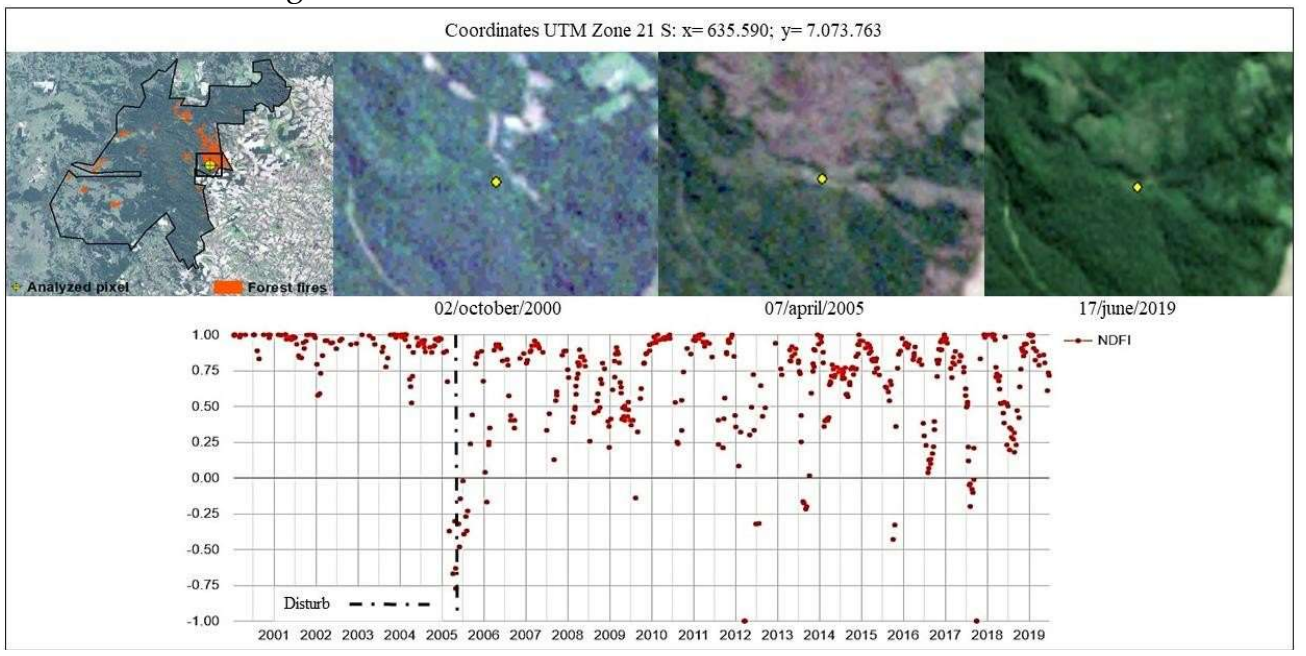

Figure 2. Temporal response of a pixel subjected to degradation due to the occurrence of forest fires, year 2005.

During the period from 2000 to 2004, the NDFI index registers annual averages between 0.86 and 0.97 , indicating that the vegetation does not report signs of being degraded. For the month of March 2005, immediately after the occurrence of the forest fires, the minimum value reported is -0.38 . This indicates that the area is very degraded, because the decrease in the values was very drastic with respect to values registered for previous years and the range considered for the study.

Subsequently, for the period from 2006 to 2011, average annual values between 0.61 and 0.82 are registered, that shows a vegetation more recovered in relation to 2005. For the months of May 2012 and September 2017, minimum values of -1 are registered, indicating a great magnitude of degradation. The values increase since 2018 , and an average of 1 is obtained for the first semester of 2019.

This behavior, supported by satellite observations of the area, indicates a process of regrowth of forest vegetation, mainly during the last 2 years. This point out that forests pass through multiple stable states depending on the region's natural dynamics and the severity of the change with which they have evolved [20]. As forest fires are dynamic and frequent disturbances within the RPNSR, the forests subject to the fire regimes change constantly, explaining the fluctuations in the behavior of the index values for the pixel 
under study during the period 2000-2019. The time series of the NDFI index values respect to the twister that occurred in 2017 is shown in Figure 3.

Figure 3. Temporal response of a pixel subjected to degradation due to the occurrence of a twister, year 2017.

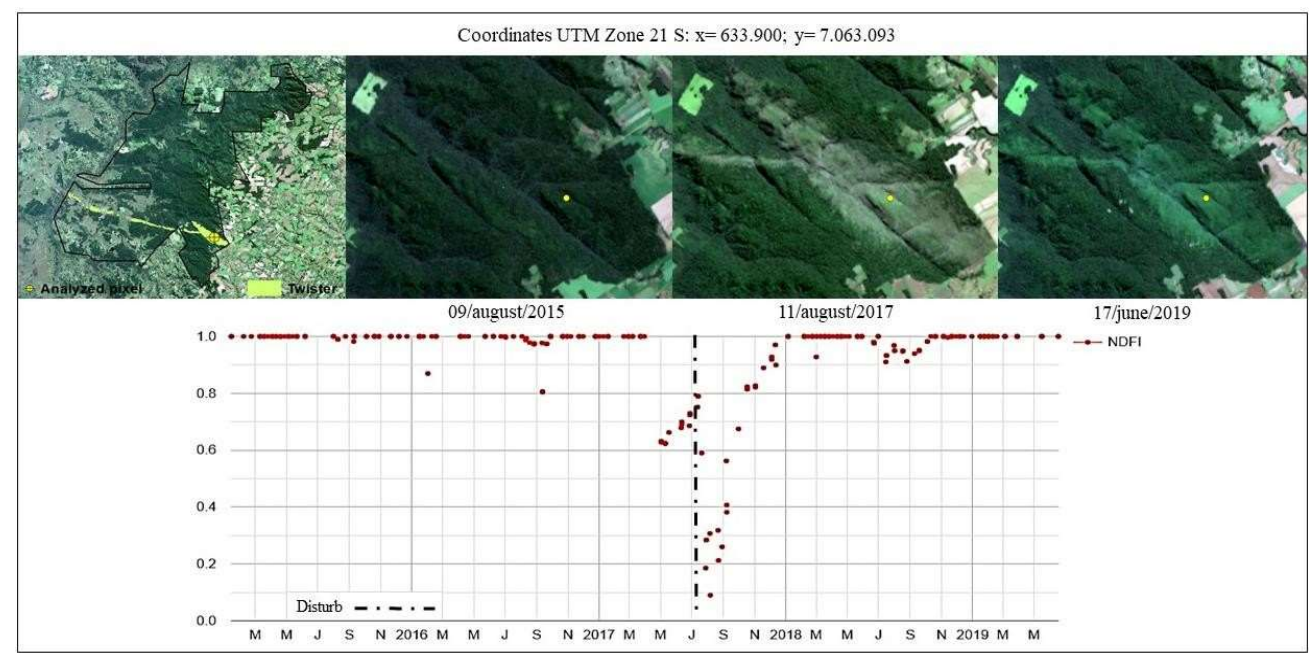

During the period from 2015 to 2016, the index values remain close to 1 and the occurrence of disturbances are not registered. Since May 2017, a decrease occurs to a minimum value of 0.06 , indicating that the area is degraded in response to the occurred twister.

The months from June to September are the most fluctuating and the response of the index values varies significantly. During the first half of 2019, recovered vegetation is observed, represented by average values of 1 .

Certain types of disturbances may shift an ecosystem from a stable to one of instability, but provided these disturbances do not occur frequently, the forest will tend to return to its original stable state through succession [20].

The time series of the NDFI index values with respect to illicit crops established up until the first semester of 2019 is shown in Figure 4.

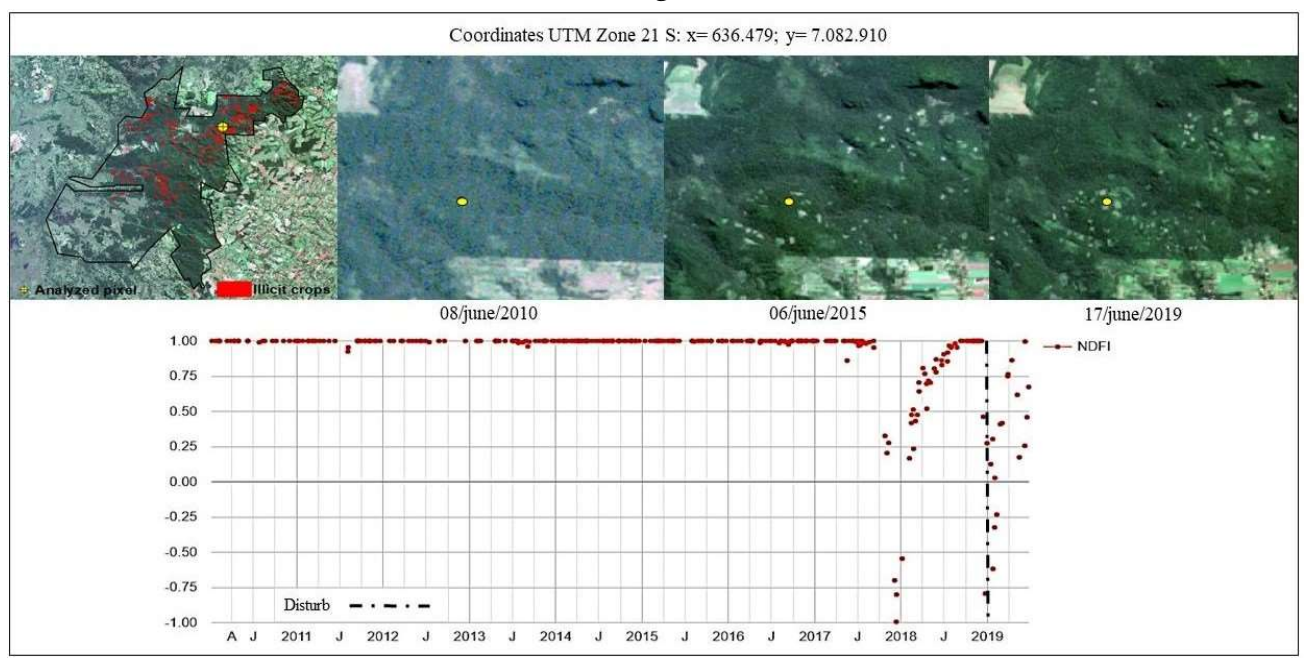

Figure 4. Temporal response of a pixel subjected to degradation due to the establishment of illicit crops until 2019.

It is observed that during the period from 2010 to 2017, the NDFI index registers average annual values between 0.86 and 1 , and the vegetation reports signs of not being 
altered. The first significant decrease in the values is observed during the month of October 2017 , with a minimum value of -1 .

Subsequently, a further decline in the index values was detected to a minimum of 0.76 at the end of November 2018. The satellite corroboration allows this behavior to be attributed to the phenology of Cannabis sp. illicit crops, that is shown in Figure 5.

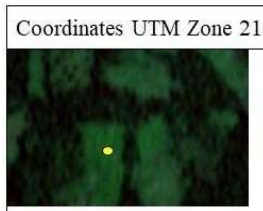

15 november 2018

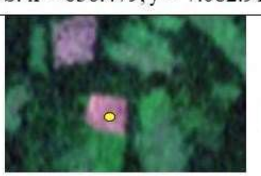

17 december 2018

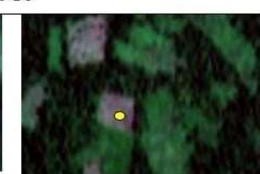

13 february 2019

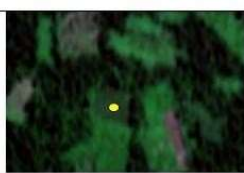

09 april 2019
Sentinel-2 L1C Image

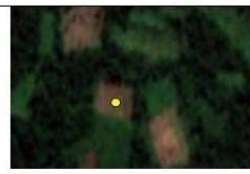

26 may 2019

Figure 5. Phenology of Cannabis sp. illicit crops in RPNSR year 2019.

The productive cycle of Cannabis sp. lasts approximately 3 months and begins between the months of October and December, when the conditions of light and precipitation become optimal. It begins with a process of controlled burning or "thinning", because this type of crops is not established in fields in which previously it was sown in a traditional way, but clearings are opened in the forest to settle there. This justifies the very low values observed during the month of December 2018.

The cycle continues with sowing and the growth period of the plantation, during which time the values increase due to the increase in the proportion of photosynthetically active vegetation. The harvest takes place from February to May, and this supports the decrease in the values of the NDFI index during May 2019. The subsequent temporal monitoring shows average values of 0.27 for the month of June 2019, indicating that the area it is degraded.

\subsection{Analysis of forest disturbances in terms of magnitude of degradation}

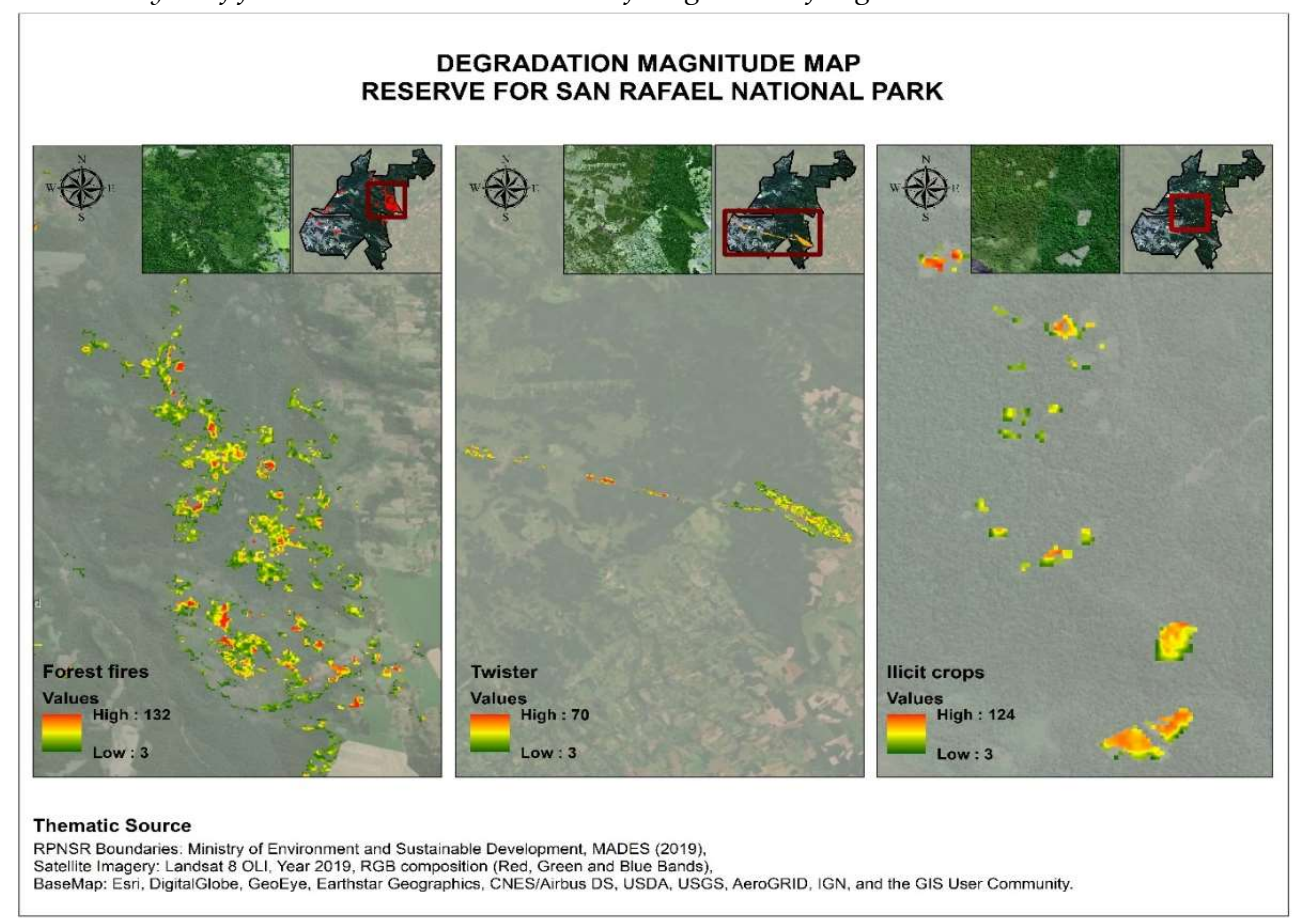

Figure 6. Magnitude of degradation of the analyzed disturbances 
The forest fires that occurred in 2005 report the maximum magnitude value among the 3 disturbances analyzed, with a value of 132 (Figure 6). The areas with reddish coloration are classified as critical and with a high magnitude of impact, therefore they have a lower resilience potential. These could coincide with those points from which the fires spread or areas where the fires were concentrated for a longer time. Other factors also influence, such as floristic composition, atmospheric humidity, temperature, wind direction and the slope of the terrain.

On the other hand, the intermediate to low magnitudes are registered in areas in which the fires did not have a serious impact, so their resilience potential is higher. They are located around the areas classified as critical. Due to the location of the fires, it can be said that they are closely related to the burning of weedy areas for the establishment of crops in the Reserve buffer zone, because these forests are bordering large extensions of areas destined for agricultural use.

Next, the second most significant disturbance in terms of registered values is the illicit crops observed until the first semester of 2019, which reported a maximum value of 124 . The areas with reddish coloration are classified as critical and with a high magnitude of affectation, in which the implementation of these activities causes serious incidence. These are mainly observed in fallows and areas recently abandoned after being harvested, therefore they are devoid of vegetation. The yellowish-greenish coloration is observed in areas that presents less magnitude of affectation. Such behavior is due to the existence of vegetation cover, and depending on the phenological state of the crop, a high response in photosynthetic activity can occur, resembling forests in this aspect, but not in terms of composition and structure.

Lastly, the disturbance that registered the least significant value of magnitude is the twister that occurred in 2017, which reports a maximum value of 72 . Areas with higher magnitudes are classified as critical, because they were the most affected and the climatic phenomenon could have manifested with higher intensity. These zones coincide with the central areas in which the tornado passed through and they have a lower resilience potential. On the other hand, areas that register intermediate to low magnitudes are classified as moderately critical, due to the pass of the storm did not directly affect these areas. They are located around critical areas, and they have the highest potential for resilience.

According to data from the Station of the Meteorology and Hydrology Direction (2017), located at the Air Base "Cnel. DEM José María Argaña" from the District of Capitán Meza, Itapúa, the maximum wind direction on 04/26/2017, in which the disturbance was registered at night, corresponds to $149^{\circ}$ in the northwest direction [21]. This can be considered an important factor because it coincides with the trajectory followed by the climatic phenomenon.

\section{Conclusions}

The multitemporal analysis of the NDFI index with respect to the disturbances analyzed in the study area shows that the post-disturbance regeneration process tends to occur immediately in terms of remote sensing. The CODED algorithm detected degradation events after the disturbance of interest, in this case forest fires, for which the response in terms of degradation- regeneration is highly variable. On the other hand, in the case of the twister and illicit crops, the behavior is related to the factors that depends of the nature of each disturbance, in the first case, to the severity of the climatic phenomenon, and in the second, to the dynamism of the affected areas by illicit crops that responds both to the phenology of the crops and to the constantly migratory nature of these activities.

In terms of magnitude, forest fires reported the maximum values, indicating a high impact on the pixel selected for the study, taking into account that this phenomenon is of high occurrence within the Reserve. Next, the pixel selected to analyze illicit crops reported the maximum magnitude values during the thinning/burning stages of the forested areas and in the harvest stage. 
The decrease in magnitude with respect to the previous disturbance can be related to the fact that a degradation event in a pixel, it did not result in a complete elimination of the forest canopy [9]. In the case of the twister, the lowest values were reported in terms of magnitude. Also the same authors attribute the observed behavior to a "temporary degradation event", directly associated with low magnitudes of impact.

\section{References}

1. Adams, J; Smith, M; Gillespie, A. 1993. Imaging spectroscopy: Interpretation based on spectral mixture analysis. In Pieters, VM; Englert, P (eds.). Remote geochemical analysis: Elemental and mineralogical composition. Cambridge University Press, New York, United States. (7):145-166.

2. Bateson, C; Asner, G; Wessman, C. 2000. Endmember bundles: A new approach to incorporating endmember variability into spectral mixture analysis. IEEE Geoscience and Remote Sensing Society 2(38):1083-1094.

3. Souza, C; Roberts, D; Cochrane, M. 2005. Combining spectral and spatial information to map canopy damage from selective logging and forest fires. Elsevier, Remote Sensing of Environment (98): 329 - 343.

4. Bullock, E. 2019. CODED Documentation Release 2.0 (en línea). 24 p. https://coded.readthedocs.io/en/latest/Title of Site. Available online: URL (accessed on Day Month Year).

5. Montellano, A; Armijo, E. 2011. Detecting forest degradation patterns in southeast Cameroon. Anais XV Simpósio Brasileiro de Sensoriamento Remoto. Curitiba, Brazil. 9 p.

6. Darmawan, Y., \& Sofan, P. (2012). Comparison of the Vegetation Indices to Detect the Tropical Rain Forest Changes Using Breaks for Additive Seasonal and Trend (BFAST) Model. International Journal of Remote Sensing and Earth Sciences (IJReSES), 9(1). https://doi.org/10.30536/j.ijreses.2012.v9.a1823

7. Wen, X; Hu, D; Dong, X; Yu, F. 2014. An Object-Oriented Daytime Land Fog Detection Approach Based on NDFI and Fractal Dimension Using EOS/MODIS Data International Journal of Remote Sensing 35(13): 4865-4880.

8. Souza, C. M., Siqueira, J. V., Sales, M. H., Fonseca, A. V., Ribeiro, J. G., Numata, I., Cochrane, M. A., Barber, C. P., Roberts, D. A., \& Barlow, J. (2013). Ten-year Landsat classification of deforestation and forest degradation in the Brazilian amazon. Remote Sensing, 5(11), 5493-5513. https://doi.org/10.3390/rs5115493

9. Bullock, E. L., Woodcock, C. E., \& Olofsson, P. (2020). Monitoring tropical forest degradation using spectral unmixing and Landsat time series analysis. Remote Sensing of Environment, 238(November), 0-1. https://doi.org/10.1016/j.rse.2018.11.011

10. Saint-Laurent, C; Carle, J. 2006. Looking Away: The Global Association on Forest Landscape Restoration. FAO (Food and Agriculture Organization of the United Nations). Unasylva, International journal of forestry and forest industries 223(57): 40-42.

11. Portillo, L; Parra, A; Balbuena, C; Soto, C. 2008. The Forest Carbon Partnership Facility (FCPF) Readiness Plan Idea Note (RPIN) Paraguay. Asunción, Paraguay. 20 p.

12. Vera, M; Esquivel, A; Peris, S. 2014. Flora of San Rafael: Guide to common trees and shrubs. University of Salamanca - Faculty of Exact and Natural Sciences, National University of Asunción - Wildlife Paraguay. Asunción, Paraguay. 48 p.

13. Cacciali, P. 2013. Diversity and habitat selection of the snake fauna in Kangüery: Area for San Rafael National Park. Guyra Paraguay, Institute of Biological Research of Paraguay. Bulletin of the National Museum of Natural History of Paraguay Vol. 17(1): 29-39.

14. MADES (Ministry of Environmental and Sustainable Development). 2019. SIGEO. http://www.mades.gov.py/sigeo/

15. Núñez, K. 2012. The herpetofauna of a fragment of the Atlantic Forest in the Department of Itapúa, Paraguay. Department of Biology, Faculty of Exact and Natural Sciences-National University of Asunción. Bulletin of the Spanish Herpetological Association 23(2): 47-52

16. Quintana, M; Duré, R; Barreto, R; Medina, M; Mandelburger, D; Motte, M; Núñez, K; Amarilla, L; Gamarra, I; Kochalka, J; Aguilar, C; Filippi, V; Rodriguez, A; Arrúa, A; Garcete, W; Coronel, L; Acuña, J; Rivarola, N; Bragayrac, E; Sosa, W. Rapid Ecological Assessment of San Rafael Reserve. 2003. Secretary of Environment, Conservation Data Center, National Museum of Natural History of Paraguay.

17. Ariza, A. 2013. Landsat 8 product description and correction: Landsat data continuity mission. Agustín Codazzi Geographical Institute. Research and Development Center - CIAF. Bogotá, Colombia. 44 p.

18. Cabrera, F; López, MJ. 2016. Viability of Landsat images (ETM + and OLI) for the determination of land use conflicts in the Canton Portoviejo, Ecuador. XVII National Congress of Geographic Information Technologies. Malaga, Spain, July, 28-39.

19. Law of Protected Wild Areas n 352. Paraguay. 1994. 18 p.

20. Vásquez, A; Donoso, P; Gerding, V. 2018. Forest Degradation: ¿When Is a Forest Degraded? Forests 9 (11): 726.

21. Direction of Meteorology and Hydrology. 2017. Maximum wind of automatic stations. Asunción, Paraguay. https://www.meteorologia.gov.py/viento/index.php 